\title{
Origins of cancer symposium 2016: exploring tumor complexity
}

\author{
Matt Harlow ${ }^{1}$, Kwang-Ho Lee ${ }^{2}$ and Mary Winn ${ }^{3}$ \\ ${ }^{1}$ Department of Cancer Biology, Vanderbilt University, Nashville, TN, USA \\ ${ }^{2}$ Center for Epigenetics, Van Andel Research Institute, Grand Rapids, MI, USA \\ ${ }^{3}$ Bioinformatics and Biostatistics Core, Van Andel Research Institute, Grand Rapids, MI, USA \\ Correspondence to: Kwang-Ho Lee, email: kwangho.lee@vai.org \\ Mary Winn, email: mary.winn@vai.org \\ Keywords: tumor complexity, tumor evolution, therapy resistance, mediator, review \\ Received: September 23, $2016 \quad$ Accepted: September 25, $2016 \quad$ Published: October 03, 2016
}

\section{ABSTRACT}

\begin{abstract}
Cancer has challenged researchers with its immense complexity, from initiation to progression and on to therapeutic resistance. The seventh Origins of Cancer Symposium, held on July 22, 2016, at Van Andel Research Institute, was organized around the theme "Exploring Tumor Complexity", and the latest advances under that theme from seven leading cancer research laboratories were discussed. Here we summarize highlights from the meeting and their implications.
\end{abstract}

\section{INTRODUCTION}

The symposium began with a presentation on intratumor heterogeneity, an emerging aspect of tumor complexity. Nicolas Navin (MD Anderson Cancer Center) shared important and novel insights into how intratumor heterogeneity influences tumor evolution and therapy resistance. Using single-nucleus sequencing, Dr. Navin discovered that aneuploid rearrangements occur early in breast tumor evolution and remain highly stable during subsequent clonal expansions [1]. This observation challenges the paradigm that copy number alterations (CNAs) occur gradually and continuously during the course of tumor progression [2, 3]. His laboratory also discovered that, unlike CNAs, point mutations evolved continuously over time, leading to extensive clonal diversity, i.e., a large number of rare subclonal $(<1 \%)$ mutations that may play an important role in tumor evolution and therapy resistance [4]. Dr. Navin also discussed cancer mutation rates. His group found the mutation rate of an $\mathrm{ER}^{+}$breast tumor was similar to that of normal cells, whereas triple-negative breast cancer showed a mutation rate $13.3 \times$ higher [4]. These rates are substantially lower than previous estimates from bulk tumor samples [5]. Lastly, Dr. Navin demonstrated how phylogenetic trees of each tumor constructed by singlecell sequencing methods can guide targeted therapy by revealing founder mutations in the "trunk" of the tree; such founders can serve as ideal therapeutic targets because they are shared by all cells in the tumor.

Sophia Lunt (Michigan State University) switched gears toward cancer metabolism and discussed how aberrant alterations in metabolic regulators contribute to cancer progression and metastasis. Dr. Lunt put forward a proposition that the major function of enhanced aerobic glycolysis in cancer cells is to maintain high levels of glycolytic intermediates to promote cell proliferation [6]. As evidence, Dr. Lunt showed that an increase in glycolytic metabolites through inhibition of a pyruvate kinase muscle isozyme (PKM2), a key regulator of glycolysis, enhanced tumor cell proliferation [7]. This suggests that high pyruvate kinase activity may suppress tumor growth. Indeed, she went on to show that both PKM2 activation and the expression of PKM1, an isoform with high constitutive kinase activity, inhibit the growth of xenograft tumors [8]. Dr. Lunt then demonstrated that the anti-proliferative influence of high PKM activity holds true for normal cells as well by showing that PKM1 expression in primary normal cells impaired nucleotide production, leading to proliferation arrest [9]. Dr. Lunt concluded the talk with her findings on the role of SDHB, a subunit of succinate dehydrogenase, in ovarian cancer [10]. Targeted knockdown of $S d h b$ in mouse ovarian cancer cells resulted in enhanced proliferation and an epithelial-to-mesenchymal transition (E-MT) mediated by a genome-wide increase in histone methylation [10]. This work provides an insight into how $S D H$ dysfunction can promote ovarian cancer progression.

The second session of the symposium was focused on the complexities that underlie the process of transcription and novel methods for specifically targeting this process for cancer therapy. The first speaker was Dr. 
Dylan Taatjes (University of Colorado - Boulder) and his talk focused on the Mediator complex. Dr. Taatjes provided an in-depth review of what is known about the role of Mediator in transcription, with a specific focus on how this protein complex relays signals from specific transcription factors to the polymerase machinery. The latter half of his seminar detailed the efforts that have gone into drugging the Mediator complex, including one of his recent papers that identified cortistatin A as a highly specific inhibitor of CDK8 [11]. Intriguingly, they found that acute myeloid leukemia (AML) cells are highly sensitive to cortistatin A treatment. Dr. Taatjes showed that such treatment up-regulated tumor-suppressor and cell-lineage genes, and that this increase exposed a vulnerability of AML cells to the dosage of superenhancer-associated genes. In the hopes of translating this compound to the clinic, Dr. Taatjes reiterated that cortistatin A had no generally cytotoxic effects in vivo. Dr. Taatjes concluded his talk by describing recent efforts to identify substrates of CDK8, using SILAC followed by mass spectrometry [12].

The fourth speaker of the day was Dr. Rani George (Dana-Farber Cancer Institute, Harvard). Dr. George's lab is focused on neuroblastoma (NB), and her talk centered on the role of $C D K 7$ in this tumor. Dr George began by outlining the differences between cell-cycle CDKs and transcriptional CDKs. She followed with an elegant portrait of the NB field and where it stands with regard to prognostic markers and treatment options. Dr. George stressed that NB patients that have increased expression of the MYCN protein have the poorest prognosis [13]. Interestingly, the amplification of MYCN protein in NB results in MYCN accumulation at all actively transcribed genes and causes global amplification of transcription [14]. Dr. George then showed that $M Y C N$ expression and global transcription amplification are reduced by $C D K 7$ knockdown. Because of the recent characterization of THZ1 as a small molecule that irreversibly inhibits CDK7 activity, Dr. George's group sought to describe the effect of THZ1 on MYCN-amplified cells. THZ1 treatment caused a marked decrease in MYCN expression and a global decrease in transcription, but only in cells with increased MYCN expression. Dr. George identified a unique sensitivity in MYCN-amplified NB cells that correlated with the down-regulation of oncogenic driver genes regulated by superenhancers, including $M Y C N$. Importantly, the effect of THZ1 on transcription was to suppress MYC-driven transcriptional programs while sparing other transcriptional programs. In agreement with this observation, Dr. George noted that there was no observable off-target toxicity of THZ1 when administered to mice in vivo.

In the next talk, Emily Bernstein (Icahn School of Medicine at Mount Sinai) introduced attendees to the role of histone variants in cancer initiation and progression, with a particular focus on macroH2A. This histone, when incorporated into the nucleosome, serves as a transcriptional repressor. As such, Dr. Bernstein showed that macroH2A serves as repressor of melanoma progression $[15,16]$. This led to interesting work studying the role of macroH2A in pluripotency and reprogramming, which are important features of malignant melanoma. Using macroH2A-deficient mice (dKO), Dr. Bernstein showed macroH2A serves as an epigenetic barrier to reprogramming [17]. Intriguingly, $\mathrm{dKO}$ females have delayed mammary development, and this finding has led to the study of macroH2A in mammary development and breast cancer pathogenesis. Early findings have implicated macroH2 $\mathrm{A}$ in the maintenance of differentiated mammary cell populations in $\mathrm{dKO}$ mice, while macroH2A levels are decreased in invasive breast cancer. Together, these findings further highlight the importance of epigenetic regulation in the origin and progression of cancer.

David Langenau (Massachusetts General Hospital, Harvard), provided a detailed mechanistic view of how T-cell acute lymphoblastic leukemia (T-ALL) progresses and develops resistance to a therapy. Using an elegant approach of single T-ALL cell transplantation into zebrafish, his lab was able to follow the clonal evolution process of T-ALL. They observed functional variation within individual clones and found that a minority of clones gained an enhanced growth rate and leukemiapropagating potential by $\mathrm{mTORC} 1$ activation mediated through Akt pathway activation. Akt activation was also found to render cells resistant to dexamethasone. They found that this resistance was reversible by combined treatment with an Akt inhibitor. He then shared unpublished data on a putative oncogene, TOX (thymocyte selection-associated high mobility group box), that they recently identified through a transgenic screening approach. They found that TOX exacerbates the onset of leukemia when co-overexpressed with MYC and that TOX is overexpressed in $95 \%$ of human T-ALL by a superenhancer containing TAL1 and MYB. This high incidence suggests that the overexpression of TOX might be an initiating event of T-ALL. He then presented evidence that TOX exerts its oncogenic function by inducing genomic instability through acting as a negative regulator of KU70/80.

Susan Rosenberg (Baylor College of Medicine) brought the day to a close by bringing an evolutionary biology perspective to the regulation of mutagenesis in cancer cells. Challenging a model of random mutagenesis, Dr. Rosenberg presented work implicating stress and genomic location as nonrandom mechanisms of mutagenesis using E. coli as a model. Specifically, three stress responses regulate mutagenesis - the starvation or general stress response/RpoS [18], the SOS DNA damage response [19], and membrane protein stress or UPR [20] — through mutagenic break repair [21-23]. Dr. Rosenberg has shown that one mechanism responsible for 
mutagenic break repair is the switching from high-fidelity to error-prone double-strand-break repair through the polymerase DinB [24]. Further work has shown that the stress response is necessary to induce mutagenesis in the presence of double-strand breaks [25]. Further, mutation clusters localize to double-strand break sites [26], with the potential for mutations to occur at actively transcribed regions and transcriptional R-loops [27]. Overall, mutagenic break repair is regulated by a large network of genes [28] and is a common theme among yeast, flies, humans, and cancer cells. New findings are implicating drugs, particularly those that induce double-strand breaks, in the evolution of mutations, sending us home with the message that we need to hit the process (i.e., mutagenic stress response) - rather than the products of evolutionin order to overcome drug resistance.

This year's Origins of Cancer symposium was organized around the concept that cancer is not a simple disease that can be addressed with a single solution. With that in mind, the symposium highlighted three separate but interconnected topics that capture the complexity inherent in cancer. While the themes of gene regulation, tumor heterogeneity, and tumor evolution seem disparate at the surface, the convergence of these topics has advanced our understanding of how tumors function. From these novel discoveries, new vulnerabilities might be identified and exploited therapeutically for clinical benefit.

\section{ACKNOWLEDGMENTS}

We extend our thanks to the institutional advocates of this symposium, Drs. Peter Jones, Steve Triezenberg, George Vander Woude, and Nick Duesbury. We are grateful to professional administrators at Van Andel Institute, Beth Resau, Kayla Habermehl, Jens Forsberg, and Aubrie Bruinsma, for their outstanding support. We thank David Nadziejka for carefully editing the manuscript. Financial support for the symposium was provided by Amgen, Ferris State University, Eli Lilly, Calvin College, Genentech, Michigan State University College of Human Medicine, Spectrum Health, Mager Scientific, and the Foundation for Advanced Cancer Studies. Finally, we thank the engaging speakers and attentive audience for making this symposium a success. We look forward to the eighth annual Origins of Cancer Symposium, which will be held July 21, 2016, at Van Andel Research Institute.

\section{CONFLICTS OF INTEREST} interests.

\section{REFERENCES}

1. Navin N, Kendall J, Troge J, Andrews P, Rodgers L, McIndoo J, Cook K, Stepansky A, Levy D, Esposito D, Muthuswamy L, Krasnitz A, McCombie WR, Hicks J and Wigler M. Tumour evolution inferred by single-cell sequencing. Nature. 2011; 472:90-94.

2. Fearon ER and Vogelstein B. A genetic model for colorectal tumorigenesis. Cell. 1990; 61:759-767.

3. Hoglund M, Gisselsson D, Hansen GB, Sall T and Mitelman F. Multivariate analysis of chromosomal imbalances in breast cancer delineates cytogenetic pathways and reveals complex relationships among imbalances. Cancer Res. 2002; 62:2675-2680.

4. Wang Y, Waters J, Leung ML, Unruh A, Roh W, Shi X, Chen K, Scheet P, Vattathil S, Liang H, Multani A, Zhang H, Zhao R, Michor F, Meric-Bernstam F and Navin NE. Clonal evolution in breast cancer revealed by single nucleus genome sequencing. Nature. 2014; 512:155-160.

5. Bielas JH and Loeb LA. Mutator phenotype in cancer: timing and perspectives. Environ Mol Mutagen. 2005; 45:206-213.

6. Lunt SY and Vander Heiden MG. Aerobic glycolysis: meeting the metabolic requirements of cell proliferation. Annu Rev Cell Dev Biol. 2011; 27:441-464.

7. Vander Heiden MG, Lunt SY, Dayton TL, Fiske BP, Israelsen WJ, Mattaini KR, Vokes NI, Stephanopoulos G, Cantley LC, Metallo CM and Locasale JW. Metabolic pathway alterations that support cell proliferation. Cold Spring Harb Symp Quant Biol. 2011; 76:325-334.

8. Anastasiou D, Yu Y, Israelsen WJ, Jiang JK, Boxer MB, Hong BS, Tempel W, Dimov S, Shen M, Jha A, Yang H, Mattaini KR, Metallo CM, Fiske BP, Courtney KD, Malstrom S, et al. Pyruvate kinase M2 activators promote tetramer formation and suppress tumorigenesis. Nat Chem Biol. 2012; 8:839-847.

9. Lunt SY, Muralidhar V, Hosios AM, Israelsen WJ, Gui DY, Newhouse L, Ogrodzinski M, Hecht V, Xu K, Acevedo PN, Hollern DP, Bellinger G, Dayton TL, Christen S, Elia I, Dinh AT, et al. Pyruvate kinase isoform expression alters nucleotide synthesis to impact cell proliferation. Mol Cell. 2015; 57:95-107.

10. Aspuria PJ, Lunt SY, Varemo L, Vergnes L, Gozo M, Beach JA, Salumbides B, Reue K, Wiedemeyer WR, Nielsen J, Karlan BY and Orsulic S. Succinate dehydrogenase inhibition leads to epithelial-mesenchymal transition and reprogrammed carbon metabolism. Cancer Metab. 2014; 2:21.

11. Pelish HE, Liau BB, Nitulescu, II, Tangpeerachaikul A, Poss ZC, Da Silva DH, Caruso BT, Arefolov A, Fadeyi O, Christie AL, Du K, Banka D, Schneider EV, Jestel A, Zou $\mathrm{G}, \mathrm{Si} \mathrm{C}$, et al. Mediator kinase inhibition further activates 
super-enhancer-associated genes in AML. Nature. 2015; 526:273-276.

12. Poss ZC, Ebmeier CC, Odell AT, Tangpeerachaikul A, Lee T, Pelish HE, Shair MD, Dowell RD, Old WM and Taatjes DJ. Identification of Mediator Kinase Substrates in Human Cells using Cortistatin A and Quantitative Phosphoproteomics. Cell Rep. 2016; 15:436-450.

13. Moreau LA, McGrady P, London WB, Shimada H, Cohn SL, Maris JM, Diller L, Look AT and George RE. Does MYCN amplification manifested as homogeneously staining regions at diagnosis predict a worse outcome in children with neuroblastoma? A Children's Oncology Group study. Clin Cancer Res. 2006; 12:5693-5697.

14. Chipumuro E, Marco E, Christensen CL, Kwiatkowski N, Zhang T, Hatheway CM, Abraham BJ, Sharma B, Yeung C, Altabef A, Perez-Atayde A, Wong KK, Yuan GC, Gray NS, Young RA and George RE. CDK7 inhibition suppresses super-enhancer-linked oncogenic transcription in MYCNdriven cancer. Cell. 2014; 159:1126-1139.

15. Kapoor A, Goldberg MS, Cumberland LK, Ratnakumar K, Segura MF, Emanuel PO, Menendez S, Vardabasso C, Leroy G, Vidal CI, Polsky D, Osman I, Garcia BA, Hernando E and Bernstein E. The histone variant macroH2A suppresses melanoma progression through regulation of CDK8. Nature. 2010; 468:1105-1109.

16. Vardabasso C, Hake SB and Bernstein E. Histone variant H2A.Z.2: A novel driver of melanoma progression. Mol Cell Oncol. 2016; 3:e1073417.

17. Gaspar-Maia A, Qadeer ZA, Hasson D, Ratnakumar K, Leu NA, Leroy G, Liu S, Costanzi C, Valle-Garcia D, Schaniel C, Lemischka I, Garcia B, Pehrson JR and Bernstein E. MacroH2A histone variants act as a barrier upon reprogramming towards pluripotency. Nat Commun. $2013 ; 4: 1565$.

18. Lombardo MJ, Aponyi I and Rosenberg SM. General stress response regulator RpoS in adaptive mutation and amplification in Escherichia coli. Genetics. 2004; 166:669680.

19. McKenzie GJ, Harris RS, Lee PL and Rosenberg SM. The
SOS response regulates adaptive mutation. Proc Natl Acad Sci U S A. 2000; 97:6646-6651.

20. Gibson JL, Lombardo MJ, Thornton PC, Hu KH, Galhardo RS, Beadle B, Habib A, Magner DB, Frost LS, Herman C, Hastings PJ and Rosenberg SM. The sigma(E) stress response is required for stress-induced mutation and amplification in Escherichia coli. Mol Microbiol. 2010; 77:415-430.

21. Harris RS, Longerich S and Rosenberg SM. Recombination in adaptive mutation. Science. 1994; 264:258-260.

22. McKenzie GJ, Lee PL, Lombardo MJ, Hastings PJ and Rosenberg SM. SOS mutator DNA polymerase IV functions in adaptive mutation and not adaptive amplification. Mol Cell. 2001; 7:571-579.

23. Rosenberg SM, Longerich S, Gee P and Harris RS. Adaptive mutation by deletions in small mononucleotide repeats. Science. 1994; 265:405-407.

24. Ponder RG, Fonville NC and Rosenberg SM. A switch from high-fidelity to error-prone DNA double-strand break repair underlies stress-induced mutation. Mol Cell. 2005; 19:791804.

25. Shee C, Gibson JL, Darrow MC, Gonzalez C and Rosenberg SM. Impact of a stress-inducible switch to mutagenic repair of DNA breaks on mutation in Escherichia coli. Proc Natl Acad Sci U S A. 2011; 108:13659-13664.

26. Shee C, Gibson JL and Rosenberg SM. Two mechanisms produce mutation hotspots at DNA breaks in Escherichia coli. Cell Rep. 2012; 2:714-721.

27. Wimberly H, Shee C, Thornton PC, Sivaramakrishnan P, Rosenberg SM and Hastings PJ. R-loops and nicks initiate DNA breakage and genome instability in non-growing Escherichia coli. Nat Commun. 2013; 4:2115.

28. Al Mamun AA, Lombardo MJ, Shee C, Lisewski AM, Gonzalez C, Lin D, Nehring RB, Saint-Ruf C, Gibson JL, Frisch RL, Lichtarge O, Hastings PJ and Rosenberg SM. Identity and function of a large gene network underlying mutagenic repair of DNA breaks. Science. 2012; 338:13441348. 